\title{
RADIOLOGICAL EVALUATION OF RADIAL BONE DEFECTS TREATED WITH DEMINERALIZED BONE MATRIX IN AN EXPERIMENTAL RABBIT MODEL
}

\author{
S. A. AUDISIO ${ }^{1}$, P. G. VAQUERO ${ }^{1}$, P. A. TORRES ${ }^{1}$, E. C. VERNA ${ }^{1}$, \\ L. N. OCAMPO ${ }^{1}$, A. L. CRISTOFOLINI ${ }^{2} \&$ C. I. MERKIS ${ }^{2}$ \\ ${ }^{1}$ Faculty of Veterinary Science, National University of La Pampa, La Pampa, \\ Argentina; ${ }^{2}$ Electronic Microscopic Area, Agronomy and Veterinary Faculty, \\ National University of Río Cuarto, Córdoba, Argentina
}

\section{Summary}

Audisio, S. A., P. G. Vaquero, P. A. Torres, E. C. Verna, L. N. Ocampo, A. L. Cristofolini \& C. I. Merkis, 2015. Radiological evaluation of radial bone defects treated with demineralized bone matrix in an experimental rabbit model. Bulg. J. Vet. Med., 18, No 2, 132-139.

\begin{abstract}
Demineralized bone matrix (DBM) is often used to treat bone defects due to its osteoinductive and osteoconductive properties. The aim of this work is to evaluate the characteristics and evolution of the repair of experimental radial orthopaedic bone defects treated with DBM. DBM was prepared from rabbit bone obtained from cadavers, which were fragmented, defatted, demineralized and preserved in alcohol. Ten New Zealand rabbits were used. Critical size defects were created in one of the radiuses. The defects of 8 rabbits were filled with DBM while the other 2 rabbits did not receive any treatment. Each rabbit was radiologically followed at 15, 25, 40, 60 and 90 days. The untreated animals did not show presence of new bone in relation to the defect, whereas the DBM-treated defects were completely filled at day 90 . The presence of new bone was evident from day 15 onward until the entire defect was repaired. The production of bone at each post operative period was statistically significant $(\mathrm{P}<0.0001)$ between the control examinations on days 15,25 and 40 , while at post operative days 60 and 90 there was no significant difference $(\mathrm{P}>0.05)$. The pattern of defects' repair started with presence of new bone at the extremes of defects and continued towards their centre.
\end{abstract}

Key words: bone, demineralized bone matrix, osteotomy, rabbit, radiology, radius defect

\section{INTRODUCTION}

Demineralized bone matrix (DBM) is used in veterinary orthopaedic surgery to treat bone defects, comminuted fractures, osteotomy and arthrodesis (Hoffer et al., 2008; Chow \& Balfour, 2012; Fitzpatrick et al., 2012; Coggeshall et al., 2014).
DBM is a biomaterial, which revascularises rapidly (Parikh, 2002) and has osteoinductive (Shen et al., 2010) and osteoconductive properties (Oakes et al., 2003). The osteoinductive potential generates mesenchymal cell chemotaxis and 
induces differentiation into osteoblastic progeny cells (Chakkalakal et al., 2001). DBM is osteoinductive due to the presence of bone morphogenetic protein (BMP) (Bessa et al., 2008), growth transforming factor $\beta$ (Honsawek \& Dhitiseith, 2005), osteocalcin and osteopontin (Davis et al., 2008; Yu et al., 2014) which regulate the formation of endochondral bone (Honsawek et al., 2005), even when implanted in an extra skeletal form (Ripamonti, 2009). On the other hand the osteoconductive property is due to the presence of type I collagen which constitutes the extracellular matrix (Ludwig \& Boden, 1999).

The absence of structural resistance (Iwata et al., 2002) and the significant variability of the obtained results, which are attributable to the donor source (Pietrzak et al., 2005) are some of the advantages of the DBM.

The bone demineralisation process with $0.6 \mathrm{~N}$ hydrochloric acid causes a slight alteration of the bone architecture (Figueiredo et al., 2011) decreasing the antigenic reactions and allowing the growth factors to be exposed to the site of the graft (Riley et al., 1996).

DBM stimulates osteoinduction by endochondral ossification processes similar to those occurring in the embryo and in the repair of fractures in adults (Le Geros, 1991).

Radiology is the diagnostic technique most often used to evaluate the repair of flat, long bones defects treated with various substitutes including DBM (Bigham et al., 2008; El-Daharawy et al., 2010; Üngör, 2012).

The aim of this paper is to describe the characteristics of the evolution of the process of repair of experimental orthopaedic segmental defects of critical size in rabbits treated with DBM and evaluated by means of radiological monitoring.

\section{MATERIALS AND METHODS}

\section{Experimental animals}

The experiments were performed according to the ethical standards of care of the Faculty of Veterinary Science, National University of La Pampa, Argentina. Ten (10) sexually mature male and female rabbits were used, which were divided into treatment group (TG; $n=8$ ), and control group $(\mathrm{CG} ; \mathrm{n}=2)$. The animals were kept in individual cages, fed a balanced formula and water ad libitum. After a period of habituation to the housing conditions the surgical interventions were carried out.

\section{Experimental design}

The rabbits were prepared for surgery under aseptic conditions. The animals were sedated with $0.1 \mathrm{mg} / \mathrm{kg}$ of diazepam (Diazepam $\AA$, Lab Zoovet, Argentina), $0.01 \mathrm{mg} / \mathrm{kg}$ IM acepromazine (Acedan ${ }^{\circledR}$, Lab Holliday, Argentina) and anesthetised with $40 \mathrm{mg} / \mathrm{kg}$ IM ketamine (ketamina $50 \AA$, Lab Holliday, Argentina). Additionally, regional analgesia was performed on the right thoracic limb by blocking the brachial plexus. The incision was made on the skin and subcutaneous tissue on the dorsal aspect of the forelimb and the extensor muscles of the region were dissected to expose the middle third of the shaft of the radius. Osteotomy was performed to create a defect of critical size (Sharifi et al., 2012). A critical size defect is one that due to its minimum dimensions does not heal spontaneously during the animal's life (McBride et al., 1993). Its size is equivalent to 2 times the diameter of the shaft (Hollinger \& Kleinschmidt, 1990). The size corresponding to each rabbit's defect is listed in Table 1. The bone defects of TG rabbits were filled with DBM while the CG 
Radiological evaluation of radial bone defects treated with demineralized bone matrix ....

Table 1. Length of the radius and dimensions of the critical segmental defects (length and surface area)

\begin{tabular}{lcccc}
\hline $\begin{array}{l}\text { Rabbit } \\
\text { No. }\end{array}$ & $\begin{array}{c}\text { Radial length } \\
(\mathrm{mm})\end{array}$ & $\begin{array}{c}\text { Defect length } \\
(\mathrm{mm})\end{array}$ & $\begin{array}{c}\text { Defect length / radius } \\
\text { length ratio }\end{array}$ & $\begin{array}{c}\text { Defect area } \\
\left(\mathrm{mm}^{2}\right)\end{array}$ \\
\hline Treatment group & & & & \\
1 & 69 & 8.23 & $11.92 \%$ & 27109 \\
2 & 70 & 8.38 & $11.97 \%$ & 37581 \\
3 & 69 & 7.75 & $11.23 \%$ & 22380 \\
4 & 70 & 8.19 & $11.70 \%$ & 32148 \\
5 & 72 & 7.96 & $11.05 \%$ & 32700 \\
6 & 66 & 9.58 & $14.51 \%$ & 26440 \\
7 & 70 & 8.99 & $12.84 \%$ & 26953 \\
8 & 70 & 9.80 & $14.00 \%$ & 24490 \\
\hline Control group & & & & \\
1 & 70 & 8.43 & $12.05 \%$ & 31783 \\
2 & 70 & 9.22 & $13.17 \%$ & 27240 \\
\hline
\end{tabular}

rabbits received no treatment. The limbs did not receive orthopaedic stabilisation. The extensor muscles were sutured with simple interrupted suture using polyglactin (Vicryl®), the subcutaneous tissue and skin were sutured routinely. The rabbits received 1,000,000 IU benzylpenicillin and dihydrostreptomycin (Dipenisol $\AA$, Bayer Lab, Argentina) and a nonsteroidal antiinflammatory drug (Ketofen $0.1 \mathrm{mg} / \mathrm{kg}$ (Kalmavet ${ }^{\circledR}$, Lab Vetanco, Argentina) for 3-5 days.

\section{DBM preparation}

DBM was obtained from adult rabbits' cadavers by preparing the long bones under aseptic conditions. The shafts were fragmented into pieces of 6-7 $\mathrm{mm}$ and washed with abundant distilled water at $4{ }^{\circ} \mathrm{C}$ to remove the greatest amount of organic waste. The fragments were subjected to grinding to obtain particles of about $74-420 \mu \mathrm{m}$. The ground bone remained 8 hours in chloroform-methanol mixture (1:1) with continuous agitation to facilitate the separation of lipids. Lipid- free bone was demineralized by submerging it in a solution of $0.6 \mathrm{~N}$ hydrochloric acid ( $\mathrm{HCl})(25 \mathrm{meq} \mathrm{HCl}$ per $1 \mathrm{~g}$ bone) for 18 hours with continuous agitation and periodic replacement of the acidic solution. The material was filtered through Warthman No.1 paper and washed with distilled water at $4{ }^{\circ} \mathrm{C}$ to remove excess acid and to stabilize the $\mathrm{pH}$ of the solution.

\section{Radiological evaluation}

Radiological follow-up was performed on the operated limbs at 15, 25, 40, 60 and 90 days post-surgery. Each member was $\mathrm{x}$-rayed with the animal in lateral decubitus position in lateral-medial view. Each radiograph was photographed with a 12 megapixel Kodak ${ }^{\circledR}$ digital camera. The photographs were analysed with the software Image J version 1.46r (Wayne Rasband National Institutes of Health, USA). Once the photographs were uploaded, the software tools were used to measure the surface and linear length of the defects, 
the surface occupied by the new bone to assess the evolution of defects' repair.

\section{Statistical analysis}

The data obtained with the ImageJ software were processed with the software Infostat (UCA, Argentina) to perform a descriptive statistical analysis, ANOVA and Fisher's LSD test.

\section{RESULTS}

None of the animals had complications as a result of the interventions or suffered from inflammatory oedema or fluid drainage of the operated limb. The rabbits made functional use of the operated limb 24 to 48 hours postoperatively.

The radiographic analysis showed that the radius had an average length of $69.6 \pm 1.51 \mathrm{~mm}$; the defects $-8.65 \pm 0.70$ $\mathrm{mm}$ and their surface was $28.88 \pm 4.55$ $\mathrm{mm}^{2}$. The relative ratio of the length of the defects to the length of the radius was $12.44 \pm 1.15 \%$ (Table 1). The treated defects healed after 90 days, whereas control rabbits not only showed no repair but also exhibited atrophy on the osteotomies extremes with sharpening of the bone in the same period of time (Fig. 1).
At the $15^{\text {th }}$ day post-surgery, periosteal reaction and new bone growth from both ends was observed. The images of that new bone had a slightly triangular shape oriented towards the centre of the defects, and at post operative day 25 these shapes were fused together and to the cortex immediate to the ulna. Between days 40 and 60 , the new bone occupied the entire defect and by the $90^{\text {th }}$ day the image represented the remodelling of the periosteum (Fig. 2).

By the $15^{\text {th }}$ day the new bone occupied $6.43 \pm 1.51 \mathrm{~mm}^{2}$ of the defect, equivalent to $22.47 \%$ of its surface. By the $25^{\text {th }}$ day, the bone stretched along $9.94 \pm 1.64 \mathrm{~mm}^{2}$, that is, $34.97 \%$ of the defects. By post surgery day $40,18.18 \pm 2.96 \mathrm{~mm}^{2}$ were filled, or $63.45 \%$ of the surface of the defects. Sixty days after the operation, the amount of bone comprised $26.62 \pm 7.08 \mathrm{~mm}^{2}(88.33 \%$ of the defect). Finally, by the $90^{\text {th }}$ day, the defects contained $28.72 \pm 5.00 \mathrm{~mm}^{2}$ new bone, $100 \%$ of the defect (Table 2).

The relative amount of bone quantified on the basis of surface defects at the $15^{\text {th }}$ day was $22.48 \%$ (min: 15.76; max: 28.48 ), at the $25^{\text {th }}$ day: $34.97 \%$ (min: 30.71; max: 48.45 ), at day $40: 63.45 \%$ (min: 60.56; max: 71.75). At post operative day 60 the amount of bone was

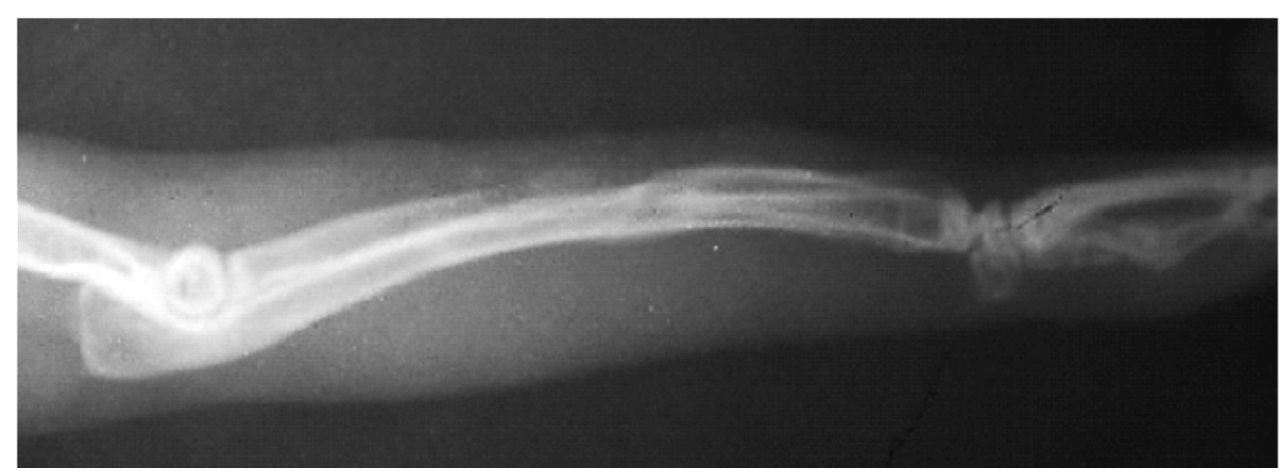

Fig. 1. Radiological latero-medial view of the radius in one of control rabbits. The defect was not repaired and the extremes of the defect were atrophied. 
Radiological evaluation of radial bone defects treated with demineralized bone matrix ....

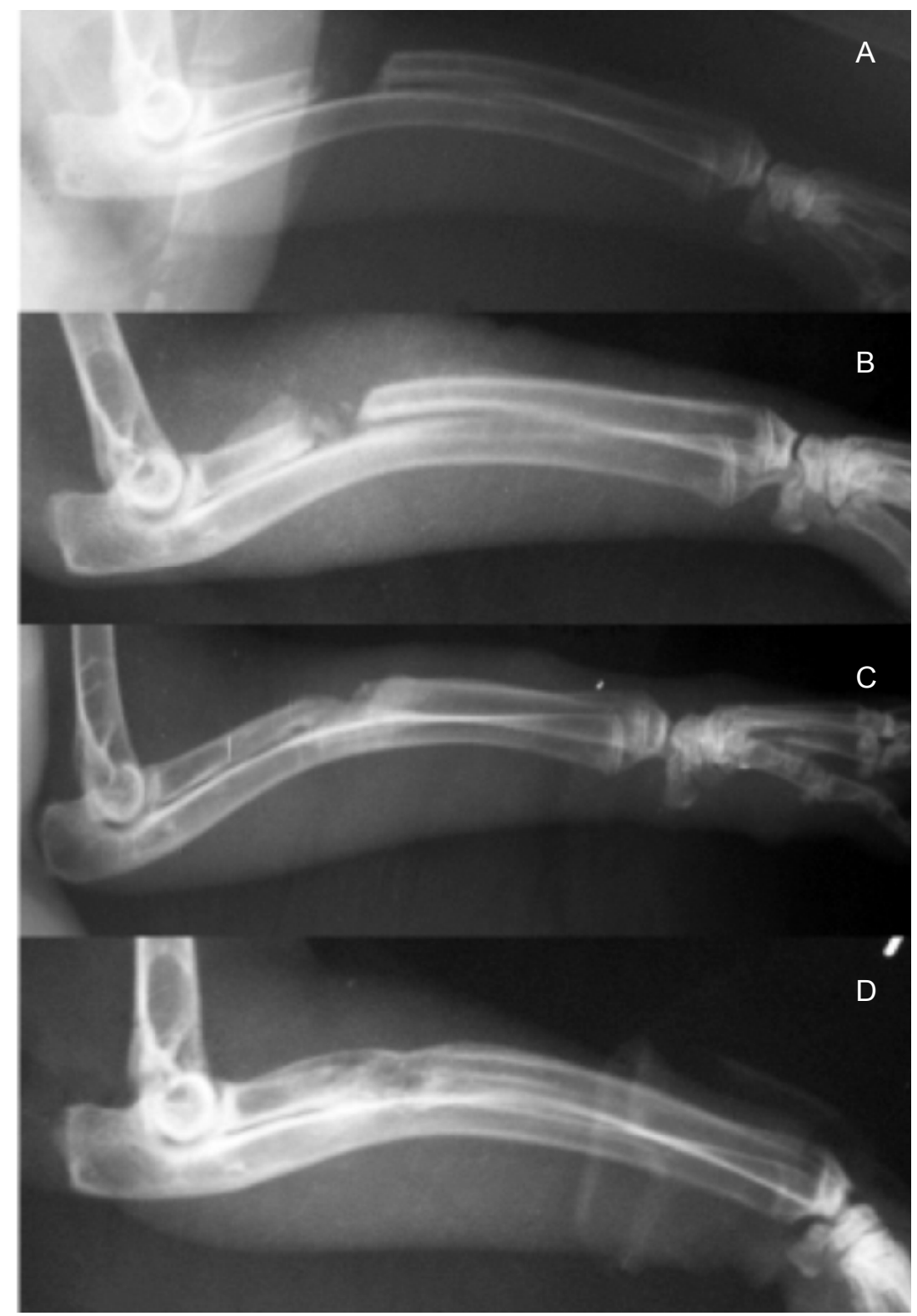

Fig. 2. Radiological control examinations of the radius in one of treated rabbits, which shows the evolution of the defect repair at post operative day 15 (A), day 25 (B), day 40 (C) and day 90 (D).

88.83\% (min: 80.02; $\max : 99.05$ ) and at day 90 - the presence of bone relative to the defect was $100 \%$, although the bone reaction promoted by the periosteum ge- nerated bony calluses which added bone volume to the region.

Statistical analysis of the results indicated significant differences between the 
Table 2. Amount of bone formed in each radiological control examination (mean \pm SD)

\begin{tabular}{lcc}
\hline Post operative period & Mean surface & Relative surface \\
\hline Day 15 & $6.43 \pm 1.51$ & $22.47 \%$ \\
Day 25 & $9.94 \pm 1.64$ & $34.97 \%$ \\
Day 40 & $18.18 \pm 2.96$ & $63.45 \%$ \\
Day 60 & $26.62 \pm 7.08$ & $88.33 \%$ \\
Day 90 & $28.72 \pm 5.00$ & $100.00 \%$ \\
\hline
\end{tabular}

control examinations performed at days 15,25 and 40, while the measurements on days 60 and 90 days did not differ significantly $(\mathrm{P}>0.05)$.

\section{DISCUSSION}

The repair and the immediate recovery of the functional use of the limb confirmed that the experimental model did not require internal or external fixation systems to stabilise the limb. The selected model avoided the use of fastening means that could have interfered with the healing process. All the experimental defects treated with DBM were cured, thus surpassing the previously reported rates of 60-100\% (Chakkalakal et al., 1999; 2001; Ozdemir et al., 2011). The ideal bone implant should be osteoconductive, osteoinductive, resorbable and radiolucent to permit the radiological assessment of bone formation and repair (Babis \& Suocacos, 2005).

The amount of production of the new bone which filled the defect was established by quantifying the real relative surface occupying the defect. Bone production was recorded from the first control and it increased until the last one.

DBM has the property of not being radiologically visible (Pryor et al., 2009). This characteristic allowed the identification of presence of new bone and the progress and evolution of the repair. The surface of the defect and the bone occupying it was established on each radiograph. As regards the interpretation of results, the authors determined the amount of new bone in relation to the measured surface.

The beginning of the repair was evident in the examination carried out by the $15^{\text {th }}$ day, in which the presence of new bone in the interior of the defects was observed. The produced bone had a triangular shape which projected from both osteotomies towards the centre of the defect. In this first stage, the amount of bone was equivalent to $22.47 \%$ of the total surface of the defect. In the study carried out at post operative day 25 , both shapes increased until they made contact and fused. During this period the amount of bone observed in the radiographs represented $63.45 \%$ of the surface of the defect. By the $90^{\text {th }}$ day, the production of bone was $100 \%$. Bone production was significant at days 15,30 and 60 days $(\mathrm{P}<0.0001)$. Between the $60^{\text {th }}$ and the $90^{\text {th }}$ day the production of new bone for repair was not significant $(\mathrm{P}>0.05)$.

Periosteal reaction in the cortical bone immediate to the osteotomies of the defect was observed by the $15^{\text {th }}$ day post-surgery, changes which are similar to the repair of fractures and small defects (Rahn, 2002).

In conclusion, the radiological evaluation of the new bone production during the repair of orthopedic critical defects treated with demineralized bone matrix followed a chronological sequence and 
became evident from the $15^{\text {th }}$ day onward. It began at the osteotomies' ends and progressed to the centre of the defect until it was filled completely at day 90. Defect repair was significant between days 15 and $40(\mathrm{p}<0.0001)$. The timing and mode of production suggested that radiologically the bone repair was produced by osteoconduction mechanisms.

\section{REFERENCES}

Babis, G. C. \& P. N. Suocacos, 2005. Bone scaffolds: The role of mechanical stability and instrumentation. Injury, 36S, S38S44.

Bigham, A. S., S. N. Dehghani, E. Z. Shafiei \& E. S. Torabi Nezhad, 2008. Xenogenic demineralized bone matrix and fresh autogenous cortical bone effects on experimental bone healing: Radiological, histopathological and biomechanical evaluation. Journal of Orthopaedics and Traumatology, 9, 73-80.

Bessa, P, M. Casal \& R. Reiss, 2008. Bone morphogenetic protein in tissue ingeneering: The road from the laboratory to the clinic. Part I (Basic concepts). Journal of Tissue Engineering and Regenerative Medicine, 2, 1-13.

Chakkalakal, D. A., B. S. Strates, A. A. Mashoof, K. L. Garvin, J. R. Novak, E. D. Frit, 1999. Repair of segmental bone defects in the rat: An experimental model of human fracture healing. Bone, 25, 321-332.

Chakkalakal, D. A., B. S. Strates, K. L. Garvin, J. R. Novak, E. D. Fritz \& T. J. Mollner, 2001. Demineralized bone matrix as a biological scaffold for bone repair. Tissue Engineering, 7, 161-177.

Chow, E. P. \& R. J. Balfour, 2012. Tarsometatarsal arthrodesis using tarsometatarsal intramedullary pin stabilization. Veterinary Surgery, 41, 733-737.

Coggeshall, J. D., D. J. Reese, S. E. Kim \& A. Pozzi, 2014. Arthroscopic-guided ulnar distraction for the correction of elbow in- congruency in four dogs. Journal of Small Animal Practice, 55, 46-51.

Davis, J., M. Tucci, L. Franklin, G. Russell \& H. Benghuzzi, 2008. The effects of growth factors on the production of ostepontin and osteoclacin. Biomedical Sciences Instrumentation, 42, 31-36.

El-Daharawy, M. H., M. H. Shekidef, I. H. Ahmed \& M. Zayed, 2010. The effect of immobilization on reconstruction of mandibular defect using free iliac crest bone graft in dogs. Nature, 8, 52-58.

Figueiredo, M., S. Cunha, G. Martins, J. Freitas, F. Judas \& H. Figueiredo, 2011. Influence of hydrochloric acid concentration on the demineralization of cortical bone. Chemical Engineering Research and Design, 89, 116-124.

Fitzpatrick, N., R. Yeadon, T. J. Smith, J. Johnson, W. I. Baltzer, R. Amils, M. Farrell, A. Frost \& I. Holsworth, 2012. Shoulder arthrodesis in 14 dogs. Veterinary Surgery, 41, 745-754.

Hoffer, M. J., D. J. Griffon, D. J. Schaeffer, A. L. Johnson \& M. W. Thomas. 2008. Clinical applications of demineralized bone matrix: A retrospective and case-matched study of seventy-five dogs. Veterinary Surgery, 37, 639-647.

Hollinger, J. O. \& J. C. Kleinschmidt, 1990. The critical size defect as an experimental model to test bone repair methods. Journal of Craniofacial Surgery, 1, 60-68.

Honsawek, S. \& D. Dhitiseith, 2005. Content of bone morphogenetic protein- 4 in human demineralized bone: Relationship to donor age and ability to induce new bone formation. Journal of the Medical Association of Thailand, 88, Suppl. 4, S260-265.

Iwata, H., S. Sakano, T. Itoh \& T. W. Bauer. 2002. Demineralized bone matrix and native bone morphogenetic protein in orthopaedic surgery. Clinical Orthopaedics and Related Research, 395, 99-109.

Le Geros, R. Z., 1991. Calcium phosphate biomaterials in preventive and restorative dentistry. In: Oral Biology and Medicine, 
ed R. Z. Le Geros, Basel, Switzerland, pp. 154-192.

Ludwig, S. C. \& S. D. Boden, 1999. Osteoinductive bone graft substitutes for spinal fusion. Orthopedic Clinics of North America, 30, 635-645.

McBride, J., M. Clyde, R. E. Banks, D. Taylor \& J. Ryan, 1993. Healing of segmental bone defects in goat tibia. Journal of Investigative Surgery, 6, 369-643.

Oakes, D. A., C. C. Lee \& J. R. Lieberman, 2003. An evaluation of human demineralized bone matrices in a rat femoral defect model. Clinical Orthopaedics and Related Research, 413, 281-290.

Ozdemir, M. T., C. Mustafa \& C. Kir, 2011. Repair of long bone defects with demineralized bone matrix and autogenous bone composite. Indian Journal of Orthopaedics, 45, 226-230.

Parikh, S. N., 2002. Bone graft substitutes: Past, present, future. Journal of Postgraduate Medicine, 48, 142-148.

Pietrzak, W. S., S. V. Perns, J. Keyes, J. Woodell-May \& N. M. McDonald, 2005. Demineralized bone matrix graft: A scientific and clinical case study assessment. Journal of Foot and Ankle Surgery, 44, 345-353.

Pryor, L. S., E. Gage, C. J. Langevin, F. Herrera, A. D. Breithaupt, C. R. Gordon, A M. Afifi, J. E. Zins, H. Meltzer, A. Gosman, 2009. Review of bone substitutes. Craniomaxillofacial Trauma \& Reconstruction, 2 , 151-160.

Rahn, B. A., 2002. Bone healing: Histologic and physiologic concepts. In: Bone in Clinical Orthopaedics, ed G. E. Fackelman, Thieme, New York, pp. 287-326.

Riley, E. H., J. M. Lane, M. R. Urist \& J R. Lieberman, 1996. Bone morphogenetic protein-2: Biology and applications. Clinical Orthopaedics and Related Research, 324, 39-46.

Ripamonti, U., 2009. Biomimetism, biomimetic matrices and the induction of bone formation. Journal of Cellular and Molecular Medicine, 13, 2953-2972.

Sharifi, D. I., H. Reza Khoushkerdar, G. Abedi, A. Asghari \& S. Hesaraki, 2012. Mechanical properties of radial bone defects treated with autogenous graft covered with hydroxyapatite in rabbit. Acta Cirurgica Brasileira, 27, 256-259.

Shen, B., A. Wei, S. Whittaker, L. A. Williams, H. Tao, D. D. Ma \& A. D. Diwan, 2010. The role of BMP-7 in chondrogenic and osteogenic differentiation of human bone marrow multipotent mesenchymal stromal cells in vitro. Journal of Cell Biochemistry, 109, 406-416.

Üngör, C., 2012. Radiologic evaluation of putty versus powder form of demineralized bone matrix in sinus floor elevation. The Journal of Oral Implantology, 38, 337-344.

Yu, S. H., H. L. Chan, L. Y. Chong, Y. H. Jheng \& P. C. Chang. 2014. Evaluaion of the osteogenic potential of growth factorrich demineralized bone matrix in vivo. Journal of Periodontology, 2, 1-16.

Paper received 30.07.2014; accepted for publication 02.10.2014

\section{Correspondence:}

\section{S. A. Audisio}

Faculty of Veterinary Science, National University of La Pampa; st 5 and 116 , General Pico, La Pampa; Argentina, e-mail: s_a_audisio@yahoo.com 